\title{
A New Method for Predicting Residual Strength of Rock in Water Diversion Tunnel Using Drilling Process Monitoring
}

\author{
Wanfei Gao (iD) 1,2 \\ ${ }^{1}$ School of Architecture, Xi'an University of Architecture and Technology, Xi'an 710055, China \\ ${ }^{2}$ State Key Laboratory of Ecohydraulics in Northwest Arid Region, Xi'an University of Technology, Xi'an 710048, China \\ Correspondence should be addressed to Wanfei Gao; gaowanfei@xaut.edu.cn
}

Received 2 September 2021; Accepted 7 January 2022; Published 21 January 2022

Academic Editor: Shaofeng Wang

Copyright $\odot 2022$ Wanfei Gao. This is an open access article distributed under the Creative Commons Attribution License, which permits unrestricted use, distribution, and reproduction in any medium, provided the original work is properly cited.

\begin{abstract}
The peak and residual strengths of rock materials are important parameters for the stability evaluation of rock engineering, especially water diversion tunnels. A friction-strengthening model based on Hoek-Brown model is proposed to determine peak and residual strength of rock. The proposed model parameter, contact friction coefficient of rock, controls the nonlinearity of the peak strength and residual strength. With a great amount of data from publications examined, the relationship between the friction coefficient and the parameters in the Hoek-Brown model is studied. A new field method using drilling process monitoring was proposed to predict the peak strength and residual strength. The results show that the predicted strength for four types of rock is in good agreement with those of the standard tests in laboratory. Their errors are within the error range of $15 \%$ compared to the results from the tested results in laboratory. Although the proposed model is empirical, the parameters in the proposed model have clear physical meaning, and it can successfully predict the peak strength and residual strength of hard rock, medium rock, and weak rock using drilling process monitoring in the field. This practical method should have a great potential for field application in rock engineering.
\end{abstract}

\section{Introduction}

The peak and residual strengths of rock materials are important parameters for the stability evaluation of rock engineering, especially for water diversion tunnels [1]. Peak strength has been well investigated, and the peak strength envelopes have been characterized using many models [2-9]. The residual strength is also related to the assessment of the stability of large-scale excavations in water diversion tunnels $[1,10]$, and the collapse properties of rock in deep tunnels for mining [11].

Many researchers have established some models for the estimation of peak and residual strengths, such as the M-C model [12], J-B model [13], GSI-softening model [14], cohesion loss model [15], and H-B failure criterion, which was proposed by Hoek and Brown [2].

$$
\sigma_{1}=\sigma_{3}+U C S \cdot\left(\frac{m \sigma_{3}}{\mathrm{UCS}}+s\right)^{a}
$$

Where $\sigma_{1}$ is the major principal stress, $\sigma_{3}$ is the minor principal stress, UCS is the unconfined compressive strength of intact rock, and $s, a$, and $m$ are material constants. For the intact rock, $m$ is equal to $m_{i}, a=0.5$, and $s=1$. These models have been used in a variety of rock engineering. However, the $\mathrm{M}-\mathrm{C}$ model can be used for the peak and residual strengths at the confining stress of $<60 \mathrm{MPa}$ due to its clear physical meaning, and it cannot describe the nonlinear strength properties of rock [15]. Due to the extent dependence of the confinement and unclear physical meaning, the $\mathrm{J}$-B model cannot describe the residual strength properties so well, that it cannot be widely applied in engineering [13]. The GSI-softening model for estimating the residual strength is largely dependent on the determination of a residual GSI [14]. It is difficult to estimate the residual strength of the most brittle rock at zero confinement. The cohesion loss model [15], only parameter and simple form, can well present the residual strength nonlinearity. The parameter lacks physical meanings and should be determined by using 
a great amount of test data [15]. Eberhardt [16] has presented the advantages and limitations of the $\mathrm{H}-\mathrm{B}$ model. The $\mathrm{H}-\mathrm{B}$ model has been widely used in most types of rock engineering due to the nonlinear capturing of the peak strength envelopes $[14,17]$. Since the H-B model can characterize the nonlinear properties over a wide range of confining stresses, it is also used to determine the residual strength of rock materials [18]. However, due to the physically incorrect reduction of $\sigma_{c}$ to a residual parameter $\sigma_{r}$, the $\mathrm{H}-\mathrm{B}$ model is not widely used to estimate the residual properties in rock engineering applications [15]. From the literature review, a reasonable model of strength envelope of rock should obey nonlinearity and the clear physical meanings of model parameters.

In this work, the friction-strengthening model is established to estimate the peak and residual strengths of rock materials. The model parameter, contact friction coefficient, has the physical meaning of rock. The relationship between the friction coefficient and the model parameters is studied by using a great amount of data collected from the literature. A new method using drilling process monitoring was proposed to predict the peak strength and residual strength. Although the proposed model is empirical, it can successfully predict the peak strength and residual strength of hard rock, medium rock, and weak rock using drilling process monitoring in the field.

\section{Data Collection}

In this study, a great amount of the peak and residual strength data were collected from 28 various rock types. Data for these rocks were obtained from the literature as shown in Table 1. Due to the cohesion lost largely in the deformation process of rock, the frictional properties of rock primarily control the residual strength $[19,20]$. The friction of rock is only dependent on rock type at high confining pressures [21]. However, frictional properties vary significantly under low confining stresses, which is relevant to most rock engineering applications $[21,22]$. Therefore, the data is collected at low confining pressures, which are lower than $60 \mathrm{MPa}$.

In addition, the four rock types (limestone, slate, granite, and red sandstone) were obtained by a drilling process by monitoring apparatus (DPM) [23]. The DPM can continuously measure and record drilling operational data such as the thrust force, torque, penetration rate, rotation speed, drilling depth, and penetration depth per rotation. The data for the four rock types (limestone, granite, slate, and sandstone; see Figure 1) were performed using a WDT Rock Mechanics Testing System [24, 25], and testing protocols in the laboratory. The samples were obtained from a water conveyance tunnel in the Weihe River Basin, Shaanxi Province, China. The rock samples are also made with a standard size (height $100 \mathrm{~mm} \times$ diameter $50 \mathrm{~mm}$ ) for the compression test. To prevent eccentric compression, the two end faces of a cylindrical sample must remain flat and coincident in the axial direction. Specifically, the end surface deviation is controlled at $\pm 0.05 \mathrm{~mm}$, and the diameter and length error cannot exceed $\pm 0.02 \mathrm{~mm}$. The peak strength and residual strength of rock specimens were obtained by triaxial compression test with the confining pressure of $5,10,15,20$, and $25 \mathrm{MPa}$.

\section{A New Method for Peak and Residual Strength Predictions Using Drilling Process Monitoring}

3.1. A Frictional Strengthening Model for Determining Peak and Residual Strengths of Rock. In general, there are two main components: frictional strength and cohesive strength for rock strength $[15,26]$. The rock deformation also referred normally to the cohesion degradation and friction mobilization [20], which have been widely used to investigate the deformability and failure of rock [27, 28]. The parameters $m_{b}$ and $s$ of the $\mathrm{H}-\mathrm{B}$ model are analogous to the cohesion and internal friction in the $\mathrm{M}-\mathrm{C}$ model, respectively. The parameter $s$ is related to the rock fragmentation [29]. The maximum and minimum value of $s$ is 1.0 and 0 , which are related to intact rock and heavily jointed or damaged rock, respectively [29]. For intact rock $s=1$, the parameter $m_{i}$ depends mainly on the lithology, crystallization degree, mineral composition, and grains of rock. The physical properties of rock have a great effect on the resistance caused by dislocation and slipping movement, namely, "friction" [29]. Due to the deformation generation, the fraction is mobilized gradually in stages I, II, and III (see Figure 2). The fractional strength gradually occupies a leading position for the rock strength. A frictional model is proposed to describe the peak strength properties of rock and can be expressed as

$$
\sigma_{1}=\sigma_{3}+\mathrm{UCS} \cdot\left[\frac{(\lambda \tan \theta+b) \sigma_{3}}{\mathrm{UCS}}+1\right]^{0.5},
$$

where $\sigma_{1}$ is the major principle stress, $\sigma_{3}$ is minor principal stress, UCS is the unconfined compressive strength of intact rock, $\lambda$ and $b$ are the model parameters, and $\tan \theta$ is the contact friction coefficient between the fracture faces of the rock, which can be determined by drilling process monitoring.

In consideration of the frictional strength mobilization in the deformation stage of rock, the damage of macroscopic fracture significantly leads to a large loss of cohesion. Figure 2 shows that the friction strength keeps almost a constant value in stage IV, and even after. The reduction of strength is due to the loss of cohesion strength. Considering its physical nature, the residual strength is purely "frictional" in nature in most cases [29]. In stage III, the fraction is related to the sliding friction between fracture surfaces. The frictional strength results from sliding, which occupies fully a leading position for the residual strength of rock. The parameter $m_{i}$ for the residual strength in the H-B model is taken as $\eta(\lambda \tan \theta+b)$. The parameter $s$ is taken as zero [15]. The frictional strength will reach the limit and be close to a constant in the residual deformation stage (see Figure 2). For intact rock $a=0.5$, a new model is proposed to capture the residual strength envelopes of rock, and it can be expressed as 
TABLE 1: Fitted parameters of the peak and residual strength using the H-B model and the proposed model.

\begin{tabular}{|c|c|c|c|c|c|c|c|c|c|c|}
\hline \multirow{2}{*}{ No. } & \multirow{2}{*}{ Rock types } & \multicolumn{3}{|c|}{ Peak strength } & \multicolumn{3}{|c|}{ Residual strength } & \multirow{2}{*}{$\begin{array}{c}\varphi \\
\left({ }^{\circ}\right)\end{array}$} & \multirow{2}{*}{$\begin{array}{c}C \\
(\mathrm{MPa})\end{array}$} & \multirow{2}{*}{ References } \\
\hline & & $\sigma_{c}$ & $m_{i}$ & $R^{2}$ & $\eta m_{i}$ & $\eta$ & $R^{2}$ & & & \\
\hline 1 & Amarelo Pais granite & 76.59 & 40.96 & 0.99 & 5.35 & 0.135 & 0.97 & 57.59 & 12.42 & Arzúa et al. [35] \\
\hline 2 & Blanco Mera granite & 131 & 37.82 & 0.982 & 5.12 & 0.131 & 0.80 & 59.52 & 18.79 & Arzúa et al. [35] \\
\hline 3 & Vilachan granite & 116.29 & 28.23 & 0.994 & 2.98 & 0.109 & 0.82 & 54.91 & 19.39 & Arzúa et al. [35] \\
\hline 4 & Blanco Mera granite & 122.73 & 41.61 & 0.9914 & 4.88 & 0.117 & 0.95 & 60.37 & 16.76 & Arzúa et al. [37] \\
\hline 5 & Stanstead granite & 136 & 25.9 & 0.982 & 3.04 & 0.117 & 0.77 & 53.20 & 24.98 & Walton [38] \\
\hline 6 & Bunt sandstone & 67 & 10.6 & 0.967 & 8.56 & 0.779 & 0.99 & 33.63 & 16.88 & Gowd [39] \\
\hline 7 & Indiana limestone buff & 74 & 3.3 & 0.99 & 3.30 & 0.751 & 0.98 & 23.09 & 24.45 & Walton et al. [40] \\
\hline 8 & Red sandstone & 93 & 6.5 & 0.99 & 2.39 & 0.424 & 0.98 & 32.91 & 25.29 & Yang et al. [41] \\
\hline 9 & Gosford sandstone & 61 & 13.3 & 0.99 & 3.30 & 0.276 & 0.93 & 40.24 & 14.14 & Masoumi [42] \\
\hline 10 & Carrara marble & 94 & 5.5 & 0.99 & 3.34 & 0.507 & 0.96 & 38.75 & 22.55 & Walton et al. [43] \\
\hline 11 & Westerly granite & 138 & 48.3 & 0.99 & 7.02 & 0.145 & 0.96 & 64.22 & 15.79 & Walton et al. [29] \\
\hline 12 & Rhyolite & 103 & 3.4 & 0.99 & 1.92 & 0.700 & 0.98 & 14.20 & 40.09 & Walton et al. [29] \\
\hline 13 & Indiana limestone gray & 49 & 7.3 & 0.99 & 7.04 & 0.779 & 0.97 & 38.21 & 9.95 & Walton et al. [29] \\
\hline 14 & Porphyry & 101 & 11.2 & 0.98 & 4.12 & 0.368 & 0.96 & 37.69 & 24.80 & Walton et al. [29] \\
\hline 15 & Rajnagar marble & 84.8 & 6.8 & 0.93 & 3.33 & 0.490 & 0.86 & 35.69 & 20.92 & Kumar et al. [44] \\
\hline 16 & Biotite chlorite schist & 67.3 & 5.4 & 0.97 & 5.40 & 0.395 & 0.62 & 31.75 & 18.60 & Kumar et al. [44] \\
\hline 17 & Purulia gneiss & 153.6 & 24.3 & 0.97 & 3.17 & 0.131 & 0.91 & 51.28 & 28.76 & Kumar et al. [44] \\
\hline 18 & Kirthai granite gneiss & 143.3 & 32.2 & 0.99 & 2.94 & 0.109 & 0.93 & 53.10 & 32.80 & Kumar et al. [44] \\
\hline 19 & Tennessee sandstone & 229.2 & 3.2 & 0.99 & 2.40 & 0.751 & 0.93 & 17.62 & 103.08 & Cuss et al. [45] \\
\hline 20 & Coal & 38.9 & 6.3 & 1 & 0.56 & 0.490 & 0.99 & 30.00 & 11.23 & Yumlu and ozbay [46] \\
\hline 21 & Sandstone & 81.3 & 22.7 & 0.98 & 3.42 & 0.151 & 0.99 & 52.00 & 14.00 & Yumlu and ozbay [46] \\
\hline 22 & Norite & 220.1 & 22.5 & 0.99 & 4.67 & 0.208 & 0.99 & 55.00 & 34.70 & Yumlu and ozbay [46] \\
\hline 23 & Quartzite & 264.8 & 54.6 & 1 & 10.19 & 0.091 & 0.99 & 68.00 & 25.74 & Yumlu and ozbay [46] \\
\hline 24 & Hejiata coal G1 & 37.7 & 7.7 & 0.89 & 3.51 & 0.456 & 0.89 & 37.80 & 9.40 & Gao and kang [47] \\
\hline 25 & Hejiata coal G2 & 37.2 & 12.6 & 0.96 & 2.81 & 0.223 & 0.88 & 44.40 & 8.00 & Gao and kang [47] \\
\hline 26 & Coarse marble & 71.2 & 5.1 & 0.99 & 2.59 & 0.507 & 0.96 & 28.00 & 22.14 & Yang et al. [48] \\
\hline 27 & Medium marble & 112.9 & 7.2 & 1 & 7.20 & 0.565 & 0.99 & 34.40 & 31.70 & Yang et al. [48] \\
\hline 28 & Sandstone & 93.3 & 7.7 & 0.99 & 5.20 & 0.675 & 0.97 & 35.40 & 28.36 & Yang et al. [48] \\
\hline
\end{tabular}

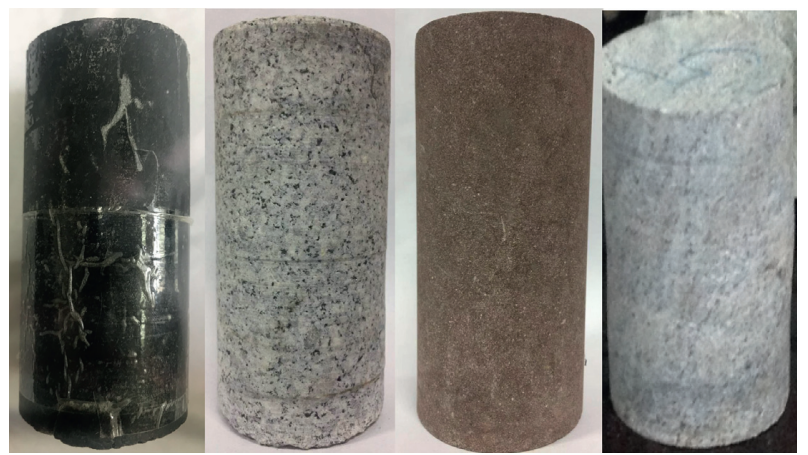

Figure 1: Rock types tested in the work (slate, granite, red sandstone, and limestone).

$$
\sigma_{1}=\sigma_{3}+\mathrm{UCS} \cdot\left[\frac{\eta(\lambda \tan \theta+b) \sigma_{3}}{\mathrm{UCS}}\right]^{0.5},
$$

where $\eta$ is a model parameter, which is mainly dependent on the fraction coefficient of rock.

\subsection{Contact Fraction Coefficient Response to Internal Friction} Coefficient of Rock. Generally, all of these drilling parameters are also related to the types of rock [4] and their mechanical properties [30]. Many researchers also conduct the drilling tests, the obtained results of which indicate the linear

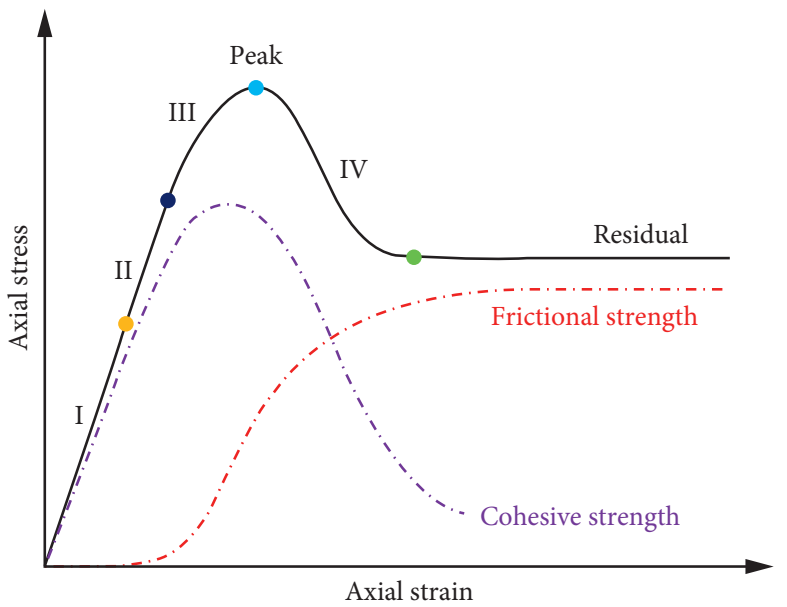

Figure 2: The frictional strength in the deformation process [29].

relation between the penetration and torque force $F_{t}[31]$. The aspect ratio of the $F_{t} \sim F_{n}$ linear curve is mainly dependent on the friction angle of the rock. The aspect ratio of $F_{t} \sim F_{n}$ linear curve is a constant as follows [30]:

$$
\frac{F_{t}}{F_{n}}=\frac{1}{\tan (a+\theta)}=H,
$$

where $\theta$ is the friction angle between the fracture faces of the rock, $H$ is the slope of $F_{t} \sim F_{n}$ linear curve and is constant, 
and $a$ is the rake angle of drilling bit cutter. After some algebraic manipulation, we have

$$
\tan a=\frac{1-H \tan \theta}{H+\tan \theta} .
$$

During the rock drilling process, the friction coefficient can be calculated as [30]

$$
\tan \varphi \prime=\frac{\tan (a+\theta)-\tan a}{1-\tan a \tan (a+\theta)}
$$

where $\varphi$ ' is the friction angle between the intact rock and compressed crushed zone. By estimating the friction angle $\varphi$ ' using (6), the internal friction angle $\varphi$ of rock is calculated as $[32,33]$

$$
\tan \varphi \prime=\frac{\pi}{2} \tan \varphi,
$$

where $\varphi$ is the internal friction angle of the rock. According to (6) and (7), the contact friction coefficient $\tan \theta$ can be calculated as

$$
\tan \theta=\tan \left[\arctan \left(\frac{\pi / 2 \tan \varphi+\tan a}{1+\pi / 2 \tan \varphi \tan a}\right)-a\right]
$$

Using (5) and (8), the variation of the contact friction coefficient $\tan \theta$ with an internal friction angle of rock $(\varphi)$ is also expressed as

$$
\tan \theta=\frac{\pi H^{2} \tan \varphi-\pi \tan \varphi}{2-2 \pi H \tan \varphi+2 H^{2}}
$$

The variation of the contact friction coefficient $\tan \theta$ with the internal friction angle of rock $(\varphi)$ can be well described. Given the aspect ratio of $F_{t} \sim F_{n}$ linear curve and the rake angle of bit cutter, the internal friction angle of rock and friction coefficient is also determined using (8) and (9).

3.3. Determination of Model Parameters. The proposed model has two dimensionless parameters $(\lambda$ and $b)$ in (2) and
(3). The function $(\lambda \tan \theta+b)$ is related to the parameter $m_{i}$ in the $\mathrm{H}-\mathrm{B}$ model [34]. The model parameters $(\lambda, b$, and $\eta)$ are determined by a great amount of the tested data from the published literature. The relationship between the contact friction coefficient and the parameter $m_{i}$ is established.

The peak strength, residual strength, cohesion, and internal friction angle of rock are mostly provided, and some are collected by interpreting the M-C model in the published literature. The $\mathrm{H}-\mathrm{B}$ model is used to fit the peak strength [29], and the proposed model in (3) is used to fit the data of the residual strength. Table 1 presents the fitted parameter $m_{i}$. Using (8), the contact friction coefficient $\tan \theta$ is calculated by using the internal friction angle of rocks in the published literature at the rake angle of bit cutter of $5^{\circ}, 10^{\circ}$, $15^{\circ}$, and $20^{\circ}$, respectively. Table 2 shows the friction angle $\theta$ and contact friction coefficient $\tan \theta$ of the proposed model. A linear relationship between the friction coefficient and the parameter $m_{i}$ is presented in Figure 3, which can be expressed as

$$
m_{i}=\lambda \tan \theta+b .
$$

The correlation coefficients $\left(R^{2}>0.95\right)$ show that the parameters $\lambda$ and $b$ can be well obtained using equation (10). The value of $\lambda$ in the proposed model is 26.296, 35.143, 45.272 , and 56.498 , and the value of $b$ is $-19.602,-23.287$, -25.7 , and -28.362 at the rake angle of bit cutter of $5^{\circ}, 10^{\circ}, 15^{\circ}$, and $20^{\circ}$, respectively. A linear relationship between the parameters $\lambda$ and $b$ of the proposed model and the rake angle of bit cutter is presented in Figure 4, which can be expressed as

$$
\begin{aligned}
& \lambda=2.0147 a+15.619, \\
& b=-0.5739 a-17.065 .
\end{aligned}
$$

The squared correlation coefficient $R^{2}$ is larger than 0.99 . Equation (11) is used to determine the parameters $\lambda$ and $b$. The frictional model for the determination of the peak strength of rock can be rewritten as

$$
\sigma_{1}=\sigma_{3}+\mathrm{UCS} \cdot\left\{\frac{[(2.0147 a+15.619) \tan \theta-0.5739 a-17.065] \sigma_{3}}{\mathrm{UCS}}+1\right\}^{0.5}
$$

Given the friction angle and the rake angle of the bit, the peak strength can be estimated using (12).

The proposed model (3) is used to fit the data of the rock residual strength. The model parameters $(\lambda, b$, and $\tan \theta)$ are obtained by (10) and (11). The model parameter $\eta$ is determined using the data collected from literature as shown in Table 1 . This parameter $\eta$ is presented as the exponential function of the friction coefficient as shown in Figure 5, which can be expressed as

$$
\eta=2.1287 m_{i}^{-0.7826}
$$

The linear correlation coefficient $R^{2}$ is larger than 0.85 . Since $m_{i}$ is accepted as a fitting parameter, whose range is from 0.001 to 25 , the range of the parameter $\eta$ is 0.17 to 474 according to (13). In addition, there are several definitions of $m_{i}$ according to different perspectives, such as the lithology, crystallization degree, and mineral composition and grains of rock. Some studies also show that parameter $m_{i}$ is linked to the tensile strength and compressive strength of rock 
TABLE 2: Summary of the calculated contact friction coefficient at the different rake angles.

\begin{tabular}{|c|c|c|c|c|c|c|c|c|c|c|}
\hline \multirow{2}{*}{ No. } & \multirow{2}{*}{ Rock types } & \multirow{2}{*}{$\varphi^{\prime}\left({ }^{\circ}\right)$} & \multicolumn{2}{|c|}{$a=5^{\circ}$} & \multicolumn{2}{|c|}{$a=10^{\circ}$} & \multicolumn{2}{|c|}{$a=15^{\circ}$} & \multicolumn{2}{|c|}{$a=20^{\circ}$} \\
\hline & & & $\theta\left(^{\circ}\right)$ & $\tan \theta$ & $\theta\left(^{\circ}\right)$ & $\tan \theta$ & $\theta\left(^{\circ}\right)$ & $\tan \theta$ & $\theta\left(^{\circ}\right)$ & $\tan \theta$ \\
\hline 1 & Amarelo Pais granite & 67.98 & 63.52 & 2.01 & 58.73 & 1.65 & 53.64 & 1.36 & 48.24 & 1.12 \\
\hline 2 & Blanco Mera granite & 69.45 & 64.91 & 2.14 & 60.07 & 1.74 & 54.94 & 1.43 & 49.52 & 1.17 \\
\hline 3 & Vilachan granite & 65.89 & 61.54 & 1.85 & 56.85 & 1.53 & 51.82 & 1.27 & 46.45 & 1.05 \\
\hline 4 & Blanco Mera granite & 70.09 & 65.51 & 2.20 & 60.65 & 1.78 & 55.51 & 1.46 & 50.08 & 1.19 \\
\hline 5 & Stanstead granite & 64.52 & 60.25 & 1.75 & 55.62 & 1.46 & 50.64 & 1.22 & 45.30 & 1.01 \\
\hline 6 & Bunt sandstone & 46.24 & 41.40 & 0.88 & 38.05 & 0.78 & 34.13 & 0.68 & 29.69 & 0.57 \\
\hline 7 & Indiana limestone buff & 33.79 & 38.17 & 0.79 & 35.08 & 0.70 & 31.41 & 0.61 & 27.17 & 0.51 \\
\hline 8 & Red sandstone & 45.46 & 43.69 & 0.96 & 40.15 & 0.84 & 36.07 & 0.73 & 31.48 & 0.61 \\
\hline 9 & Gosford sandstone & 53.04 & 49.57 & 1.17 & 45.59 & 1.02 & 41.13 & 0.87 & 36.22 & 0.73 \\
\hline 10 & Carrara marble & 51.56 & 46.94 & 1.07 & 43.15 & 0.94 & 38.86 & 0.81 & 34.09 & 0.68 \\
\hline 11 & Westerly granite & 72.90 & 68.21 & 2.50 & 63.26 & 1.98 & 58.06 & 1.60 & 52.61 & 1.31 \\
\hline 12 & Rhyolite & 21.66 & 39.17 & 0.81 & 36.00 & 0.73 & 32.24 & 0.63 & 27.94 & 0.53 \\
\hline 13 & Indiana limestone gray & 51.03 & 41.68 & 0.89 & 38.30 & 0.79 & 34.37 & 0.68 & 29.90 & 0.58 \\
\hline 14 & Porphyry & 50.50 & 47.23 & 1.08 & 43.42 & 0.95 & 39.11 & 0.81 & 34.32 & 0.68 \\
\hline 15 & Rajnagar marble & 48.44 & 45.33 & 1.01 & 41.67 & 0.89 & 37.48 & 0.77 & 32.80 & 0.64 \\
\hline 16 & Biotite chlorite schist & 44.17 & 45.63 & 1.02 & 41.94 & 0.90 & 37.73 & 0.77 & 33.03 & 0.65 \\
\hline 17 & Purulia gneiss & 62.95 & 58.78 & 1.65 & 54.22 & 1.39 & 49.29 & 1.16 & 44.00 & 0.97 \\
\hline 18 & Kirthai granite gneiss & 64.44 & 60.18 & 1.74 & 55.55 & 1.46 & 50.57 & 1.22 & 45.24 & 1.01 \\
\hline 19 & Tennessee sandstone & 26.51 & 42.25 & 0.91 & 38.82 & 0.80 & 34.85 & 0.70 & 30.35 & 0.59 \\
\hline 20 & Coal & 42.19 & 43.27 & 0.94 & 39.77 & 0.83 & 35.72 & 0.72 & 31.16 & 0.60 \\
\hline 21 & Sandstone & 63.54 & 59.44 & 1.69 & 54.85 & 1.42 & 49.90 & 1.19 & 44.59 & 0.99 \\
\hline 22 & Norite & 65.96 & 60.09 & 1.74 & 55.46 & 1.45 & 50.48 & 1.21 & 45.16 & 1.01 \\
\hline 23 & Quartzite & 75.57 & 70.77 & 2.87 & 65.76 & 2.22 & 60.53 & 1.77 & 55.08 & 1.43 \\
\hline 24 & Hejiata coal G1 & 50.61 & 47.33 & 1.08 & 43.51 & 0.95 & 39.19 & 0.82 & 34.40 & 0.68 \\
\hline 25 & Hejiata coal G2 & 56.96 & 53.20 & 1.34 & 48.97 & 1.15 & 44.30 & 0.98 & 39.22 & 0.82 \\
\hline 26 & Coarse marble & 39.85 & 42.97 & 0.93 & 39.49 & 0.82 & 35.46 & 0.71 & 30.92 & 0.60 \\
\hline 27 & Medium marble & 47.07 & 44.08 & 0.97 & 40.51 & 0.85 & 36.41 & 0.74 & 31.80 & 0.62 \\
\hline 28 & Sandstone & 48.13 & 42.64 & 0.92 & 39.19 & 0.82 & 35.18 & 0.70 & 30.66 & 0.59 \\
\hline
\end{tabular}

$[4,34]$. This implies that the parameter $\eta$ is dependent on the physical and mechanical properties of rock. Equation (13) is used to determine the model parameter $\eta$. The frictional model (3) can be written as

$$
\sigma_{1}=\sigma_{3}+\left\{2.1287 \sigma_{3} \operatorname{UCS}[(2.0147 a+15.619) \tan \theta-0.5739 a-17.065]^{0.2174}\right\}^{0.5} .
$$

Given the friction angle and rake angle of the bit, the residual strength can be estimated using (14).

\section{Verification}

A drilling process monitoring apparatus is used to measure the thrust force, torque force, penetration rate, rotation speed, and penetration depth per rotation of hard rock, medium rock, and weak rock such as granite, limestone, slate, and red sandstone. The rotation speeds of drilling are applied at 200-600 rpm for each rock type. The penetration rates of drilling are set as $0.1-1.2 \mathrm{~mm} / \mathrm{min}$. The relationships between the thrust force and torque force of each rock are obtained as presented in Figure 6. The triaxial compressive strength, triaxial residual strength, cohesion, and internal friction angle of each type of rock are obtained in the laboratory. We use these test data to verify the proposed model in predicting the peak and residual strength using drilling process monitoring in the field as presented in Figure 7.
Many drilling experimental results show a strong linear relationship between the thrust force and torque force [30]. The slope of the thrust force and torque force linear curve is mainly dependent on the internal friction angle of rock [35]. For limestone, granite, slate, and sandstone, the slopes of the thrust force and torque force linear curve are $0.6717,0.5553$, 0.6592 , and 0.758 at $a$ value of $10^{\circ}$, respectively. Using (4) or (9), the contact friction coefficient $\tan \theta$ is $1.04,1.23,1.06$, and 0.93 , respectively. Based on the proposed model, the peak strength and residual strength of the four types of rock are calculated using equations (12) and (14) as shown in Figure 7. The results show that the predicted peak strength is slightly higher than those from the ISRM standard test especially for weak rocks such as limestone and sandstone. This highness is caused by the high plastic deformity in drilling especially in soft rocks [36]. The error ranges of the predicted peak strength and residual strength of rocks are $-13.7 \%-11.8 \%$ and $-13.2 \%-14.6 \%$. Their errors are within the error range of $15 \%$ compared to the results from the standard test. Therefore, despite the slight overestimation 


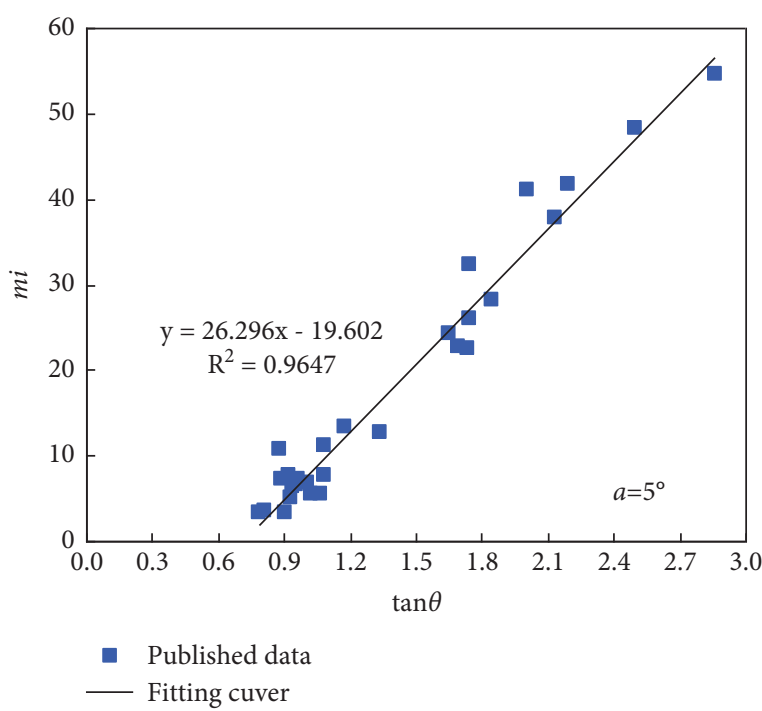

(a)

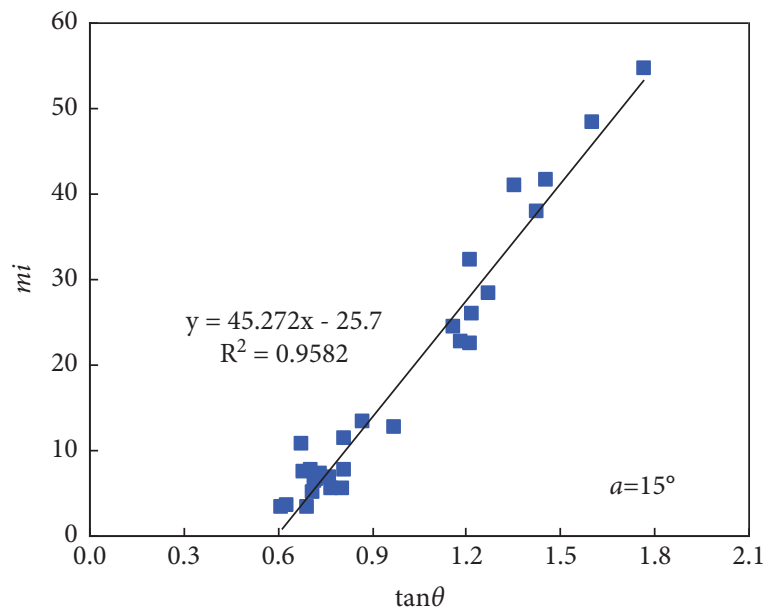

- Published data

Fitting cuver

(c)

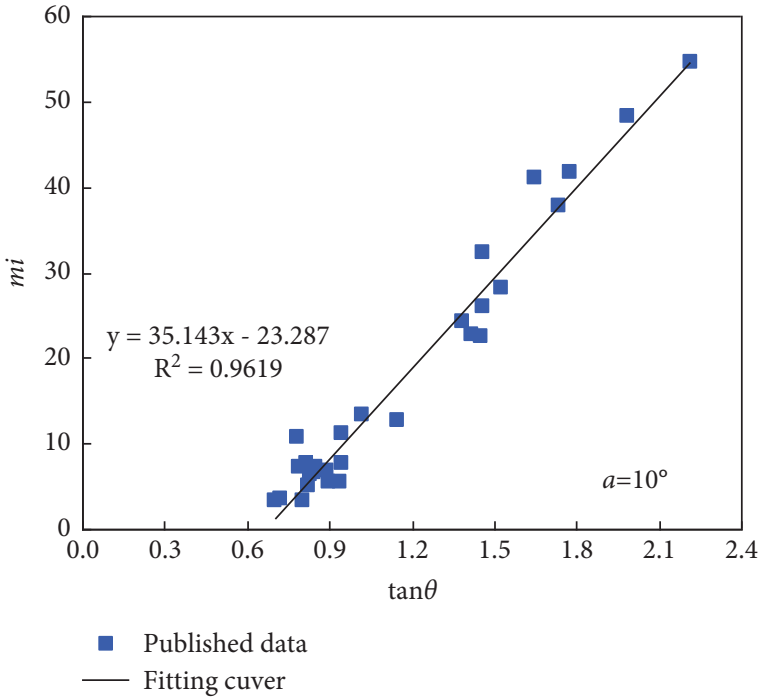

(b)

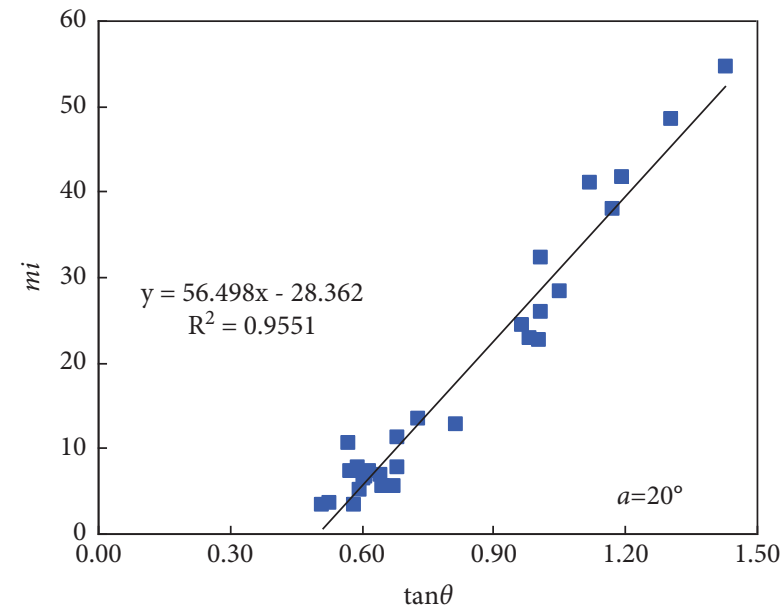

- Published data

- Fitting cuver

(d)

FIgURE 3: A linear relationship between the contact friction coefficient and the parameter $m_{i}$ of the $\mathrm{H}-\mathrm{B}$ model.

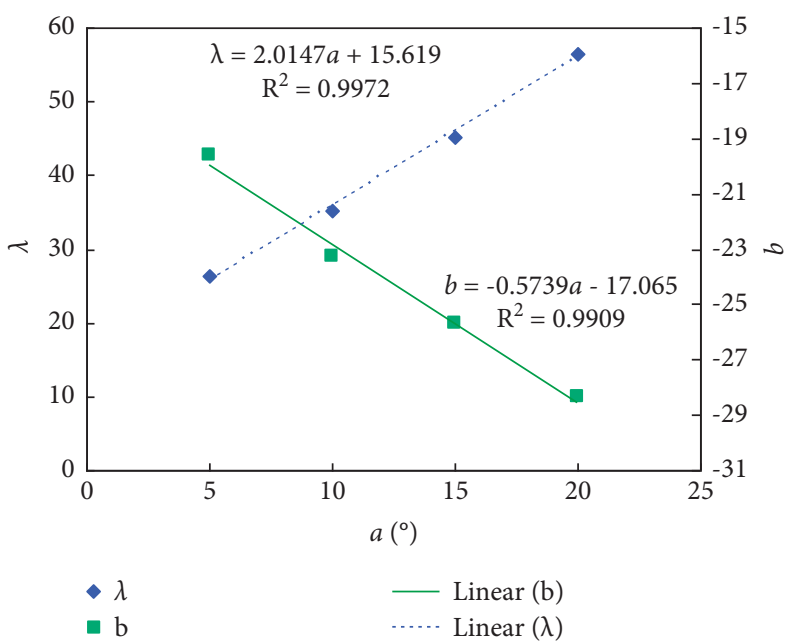

Figure 4: A linear relationship between the parameters $\lambda$ and $b$ of the proposed model and the rake angle of the bit cutter. 


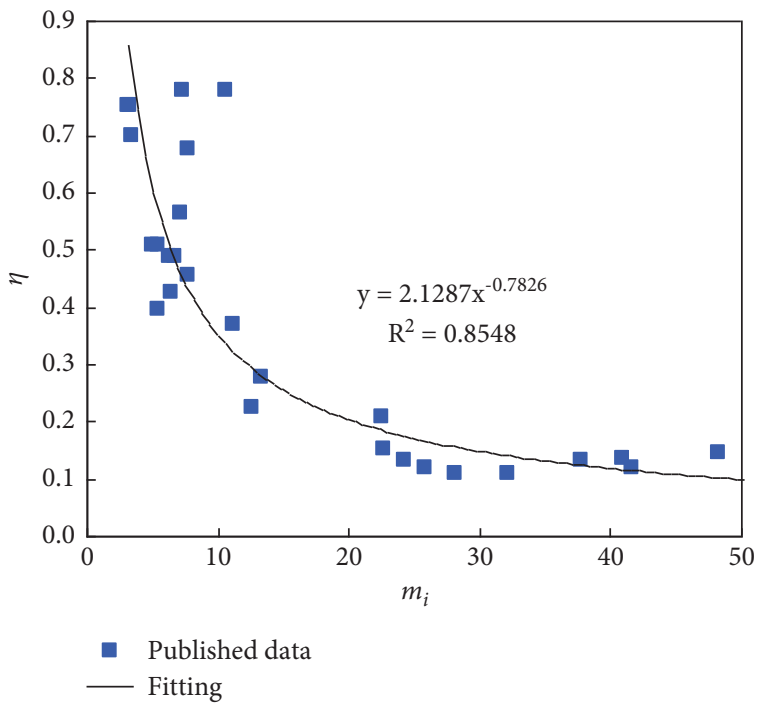

Figure 5: Correlation of the parameters $\eta$ and mi of the $\mathrm{H}-\mathrm{B}$ model.
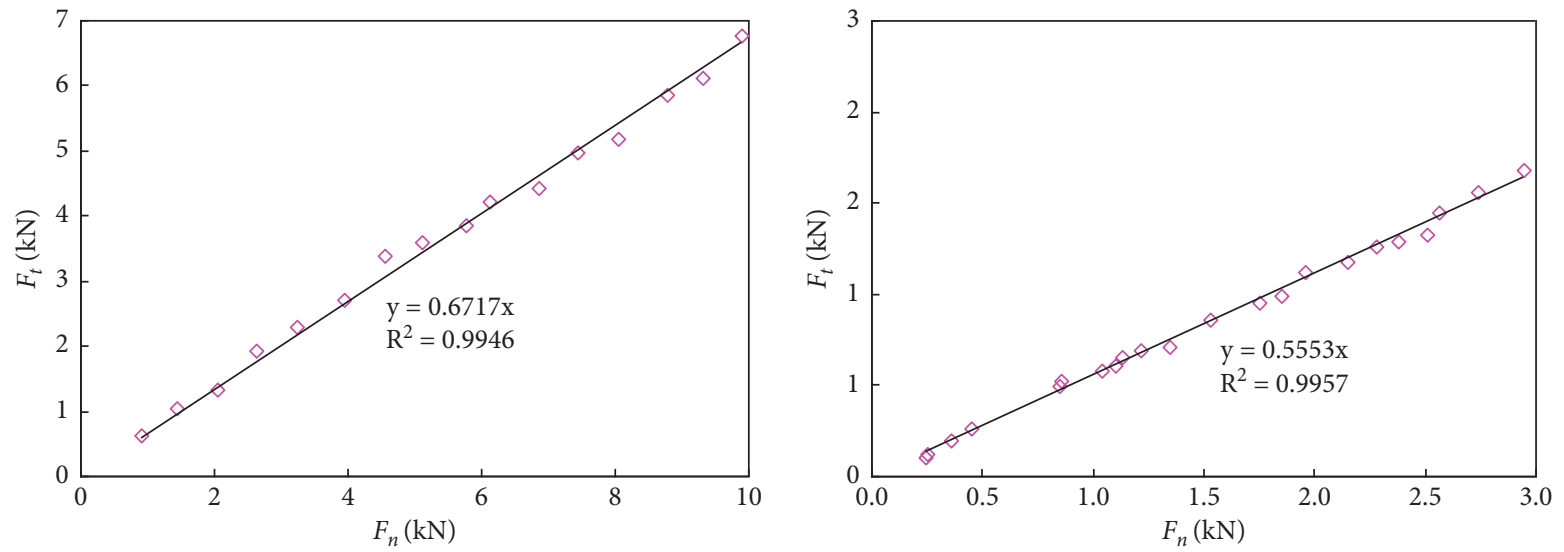

$\diamond$ Slate

Linear fitting

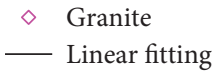

(a)

(b)
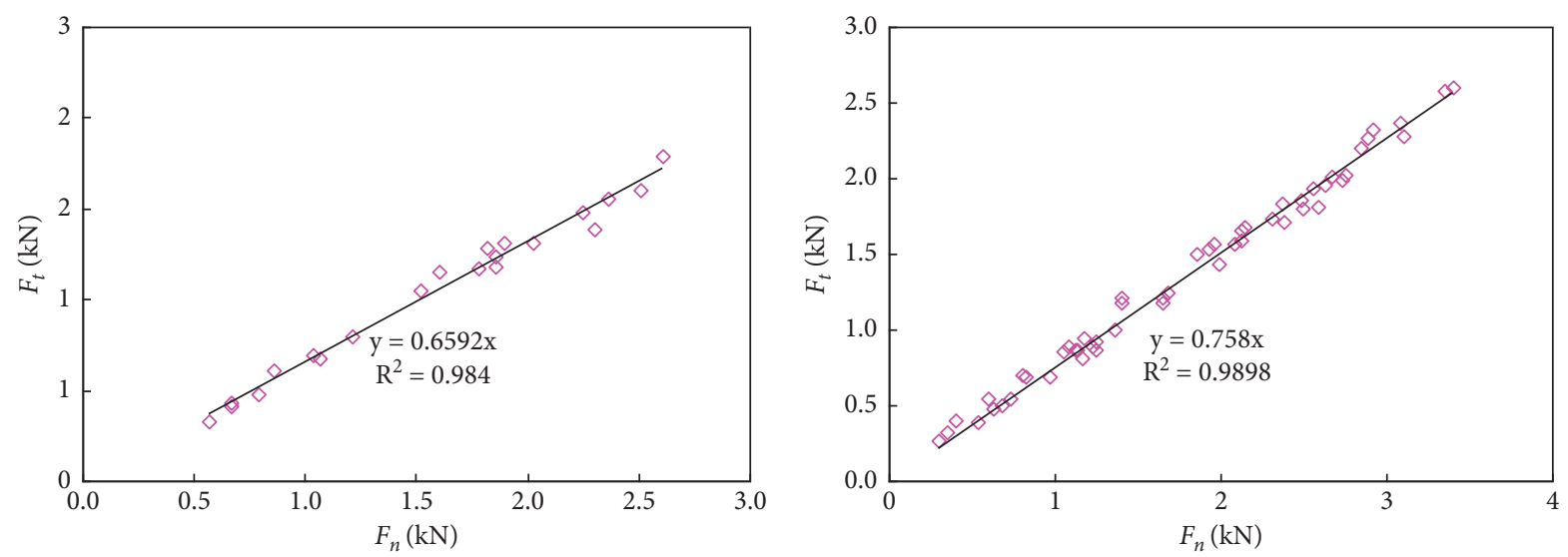

$\diamond$ Limestone

$\diamond$ Sandstone

_ Linear fitting

— Linear fitting

(c)

(d)

FIgURE 6: The thrust force-torque force curves of slate, granite, red sandstone, and limestone. 


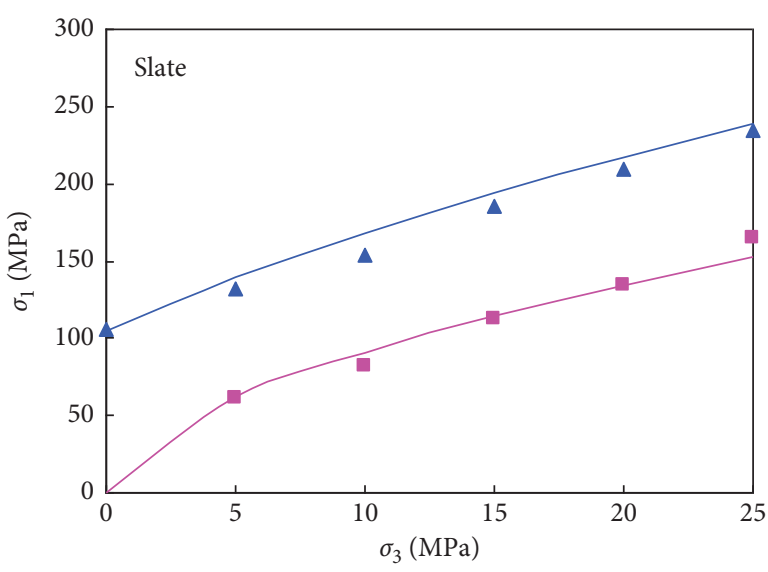

$\begin{array}{ll}\text { \ Peak strength } & \text { Prediction of peak strength } \\ \text { - Residual strength } \quad \text { Prediction of residual strength }\end{array}$

(a)

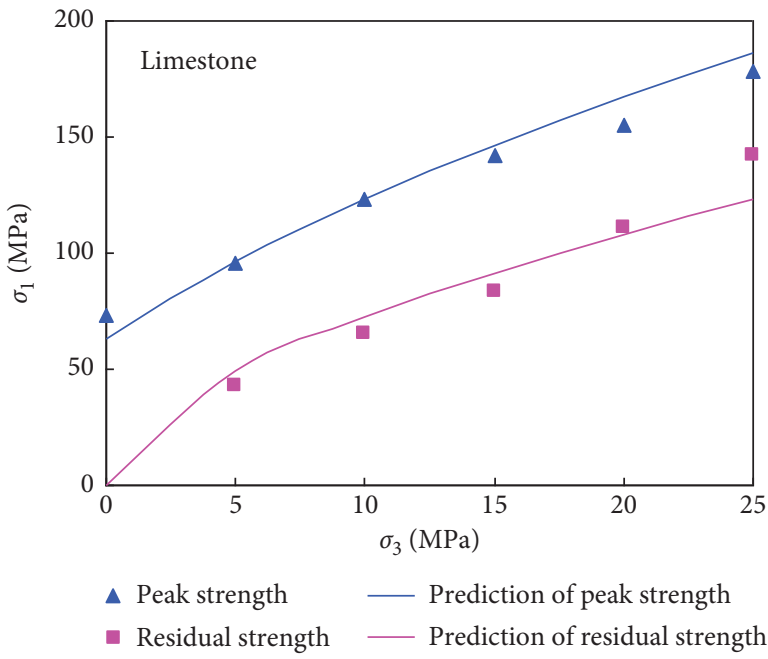

(c)

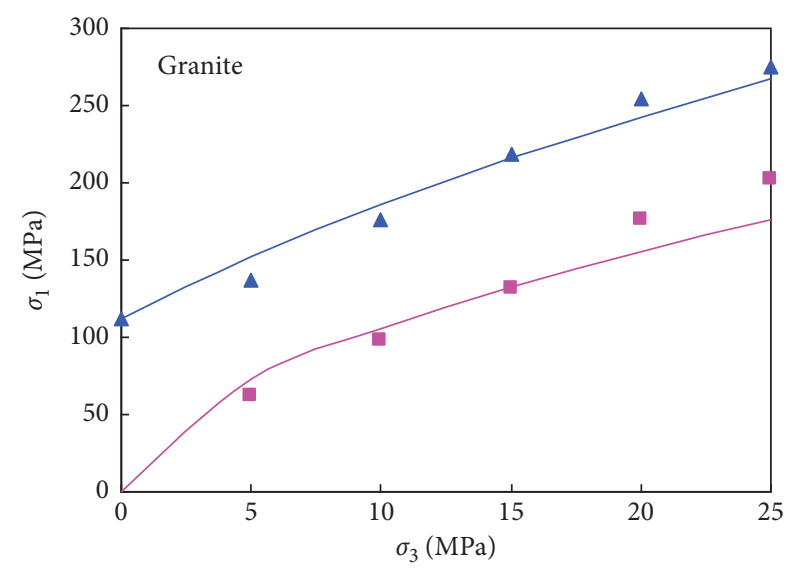

\ Peak strength _ Prediction of peak strength

- Residual strength _ Prediction of residual strength

(b)

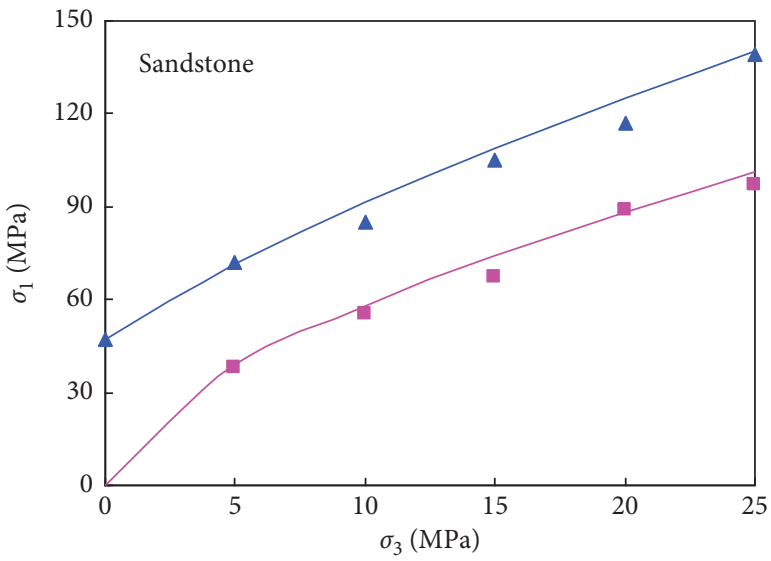

$\Delta$ Peak strength — Prediction of peak strength

- Residual strength _ Prediction of residual strength

(d)

Figure 7: The peak and residual strength data of slate, granite, red sandstone, and limestone.

(or underestimation) of rock strength owing to the existence of a boundary layer of failed rock in the cutting face and the more plastic deformity caused by the high plastic deformities during drilling, this result suggests that the method can predict the peak and residual strength.

The proposed friction-strengthening model for the peak strength has a nonlinear form and has three parameters $(\lambda, b$, and $\tan \theta)$. The parameters $(\lambda$ and $b)$ are related to the drilling parameter. The parameter $\tan \theta$ is the contact friction coefficient. They control the nonlinearity of the peak and residual strength. The value of $\lambda \tan \theta+b$ can be correlated with parameter $m_{i}$ [34]. The nonlinearity of the peak strength is generally weaker than that of the residual strength [29]. The parameter $\eta$ in the proposed friction-strengthening model can also control the strength nonlinearity. Moreover, in rock engineering applications, the new method can provide a continuous prediction for rock residual strength.
Besides, it can predict the residual strength of the rock at a speed several orders of magnitude faster than the standard test in the laboratory. Finally, owing to the minimum requirement for test preparations, this method should have a great potential for field application in rock engineering.

\section{Conclusions}

A new model is established to determine the peak strength and residual strength of rock materials. Although it is empirical, the parameter of the proposed model, the contact friction coefficient of rock, can control the nonlinearity of the peak strength and residual strength. The variation of the contact friction coefficient with the internal friction angle of rock can be well described. Given the aspect ratio of $F_{t} \sim F_{n}$ linear curve, the internal friction angle and friction coefficient of rock are also determined using the proposed model. 
With a great amount of data from publications examined, the linear relationship between the friction coefficient and the parameter $m_{i}$ is established. The frictional model was proposed to predict the peak strength and residual strength using drilling process monitoring. The predicted results are in good agreement with those of the standard laboratory test. The predicted peak strength is slightly higher than those from the ISRM standard test especially for weak rock such as limestone and sandstone. The error ranges of the predicted peak strength and residual strength of rocks are $-13.7 \%$ $11.8 \%$ and $-13.2 \%-14.6 \%$, respectively. It can successfully predict the peak strength and residual strength of hard rock, medium rock, and weak rock using drilling process monitoring in the field. This method should have a great potential for field application in rock engineering.

\section{Data Availability}

All data, models, and codes that support the findings of this study are available from the corresponding author upon reasonable request.

\section{Conflicts of Interest}

The authors declare no conflicts of interest.

\section{Acknowledgments}

This study was sponsored by the Shaanxi Provincial Department of Education Key Scientific Research Project (Grant no. 20JT054). The financial support provided by this sponsor is greatly appreciated.

\section{References}

[1] M. Cai, P. K. Kaiser, Y. Tasaka, and M. Minami, "Determination of residual strength parameters of jointed rock masses using the GSI system," International Journal of Rock Mechanics and Mining Sciences, vol. 44, no. 2, pp. 247-265, 2007.

[2] E. Hoek and E. T. Brown, "Practical estimates of rock mass strength," International Journal of Rock Mechanics and Mining Sciences, vol. 34, no. 8, pp. 1165-1186, 1997.

[3] S. Wang, X. Li, J. Yao et al., "Experimental investigation of rock breakage by a conical pick and its application to nonexplosive mechanized mining in deep hard rock," International Journal of Rock Mechanics and Mining Sciences, vol. 122, no. 2, Article ID 104063, 2019.

[4] E. Hoek and E. T. Brown, "The Hoek-Brown failure criterion and GSI - 2018 edition," Journal of Rock Mechanics and Geotechnical Engineering, vol. 11, no. 3, pp. 445-463, 2019.

[5] H. Saroglou and G. Tsiambaos, "A modified Hoek-Brown failure criterion for anisotropic intact rock," International Journal of Rock Mechanics and Mining Sciences, vol. 45, no. 2, pp. 223-234, 2008.

[6] M. Singh, A. Raj, and B. Singh, "Modified Mohr-Coulomb criterion for non-linear triaxial and polyaxial strength of intact rocks," International Journal of Rock Mechanics and Mining Sciences, vol. 48, no. 4, pp. 546-555, 2011.

[7] S. Wang, L. Sun, X. Li et al., "Experimental investigation of cuttability improvement for hard rock fragmentation using conical cutter," International Journal of Geomechanics, vol. 21, no. 2, Article ID 06020039, 2021.
[8] M. Singh, N. K. Samadhiya, A. Kumar, V. Kumar, and B. Singh, "A nonlinear criterion for triaxial strength of inherently anisotropic rocks," Rock Mechanics and Rock Engineering, vol. 48, no. 4, pp. 1387-1405, 2015.

[9] X. Si, F. Gong, X. Li, S. Wang, and S. Luo, "Dynamic MohrCoulomb and Hoek-Brown strength criteria of sandstone at high strain rates," International Journal of Rock Mechanics and Mining Sciences, vol. 115, pp. 48-59, 2019.

[10] J. Peng, M. Cai, G. Rong, M.-D. Yao, Q.-H. Jiang, and C.-B. Zhou, "Determination of confinement and plastic strain dependent post-peak strength of intact rocks," Engineering Geology, vol. 218, pp. 187-196, 2017.

[11] D. Labrie, "Frictional properties of rocks as a function of rock type, specimen size and confining pressure," in The 51st US Rock Mechanics SymposiumAmerican Rock Mechanics Association, California, USA, 2017.

[12] J. F. Labuz and A. Zang, "Mohr-coulomb failure criterion," in The ISRM Suggested Methods for Rock Characterization, Testing and Monitoring: 2007-2014, pp. 227-231, Springer, Berlin, NY, USA, 2012.

[13] T. G. Joseph, Estimation of the Post-failure Stiffness of Rock, Edmonton, Alberta, [Ph.D. Thesis], University of Alberta, 2000.

[14] J. Peng, G. Rong, M. Cai, C. B. Zhou, and W. Du, "Simulating brittle failure of rocks by a new strain-softening model," in Proceedings of the Paper 715 Proceedings Of the 47th US Rock Mechanics/Geomechanics Symposium, San Francisco, CA, USA, June 2013.

[15] J. Peng and M. Cai, "A cohesion loss model for determining residual strength of intact rocks," International Journal of Rock Mechanics and Mining Sciences, vol. 119, pp. 131-139, 2019.

[16] E. Eberhardt, "The Hoek-Brown failure criterion," in The ISRM Suggested Methods for Rock Characterization, Testing and Monitoring: 2007-2014, pp. 233-240, Springer, Berlin, NY, USA, 2012.

[17] J. Peng, G. Rong, M. Cai, X. J. Wang, and C. B. Zhou, "An empirical failure criterion for intact rocks," Rock Mechanics and Rock Engineering, vol. 47, no. 2, pp. 347-356, 2014.

[18] F. Gao and H. Kang, "Experimental study on the residual strength of coal under low confinement," Rock Mechanics and Rock Engineering, vol. 50, no. 2, pp. 285-296, 2017.

[19] J. C. Jaeger, "Behavior of closely jointed rock," in The 11th US Symposium on Rock Mechanics (USRMS), American Rock Mechanics Association, San Francisco, CA, USA, 1969.

[20] C. D. Martin, "Seventeenth Canadian geotechnical colloquium: the effect of cohesion loss and stress path on brittle rock strength," Canadian Geotechnical Journal, vol. 34, no. 5, pp. 698-725, 1997.

[21] J. Byerlee, "Friction of rocks," Rock Friction and Earthquake Prediction, vol. 116, no. 4-5, pp. 615-626, 1978.

[22] N. Barton, "The shear strength of rock and rock joints," International Journal of Rock Mechanics and Mining Sciences \& Geomechanics Abstracts, vol. 13, no. 9, pp. 255-279, 1976.

[23] M. He, N. Li, Z. Zhang, X. Yao, Y. Chen, and C. Zhu, "An empirical method for determining the mechanical properties of jointed rock mass using drilling energy," International Journal of Rock Mechanics and Mining Sciences, vol. 116, pp. 64-74, 2019.

[24] M. M. He, Z. Q. Zhang, and N. Li, "Deep convolutional neural networks-based method for strength parameter prediction of jointed rock mass using drilling logging data," International Journal of Geomechanics, vol. 21, no. 7, Article ID 04021111, 2021. 
[25] M. He, Z. Zhang, J. Zhu, and N. Li, "Correlation between the constant mi of Hoek-Brown criterion and porosity of intact rock," Rock Mechanics and Rock Engineering, 2021.

[26] H. Rafiei Renani and C. D. Martin, "Cohesion degradation and friction mobilization in brittle failure of rocks," International Journal of Rock Mechanics and Mining Sciences, vol. 106, pp. 1-13, 2018.

[27] V. Hajiabdolmajid, P. K. Kaiser, and C. D. Martin, "Modelling brittle failure of rock," International Journal of Rock Mechanics and Mining Sciences, vol. 39, pp. 431-441, 2002.

[28] L. Ma, H. Xu, Q. Tong, L. Dong, N. Zhang, and J. Li, "Post-yield plastic frictional parameters of a rock salt using the concept of mobilized strength," Engineering Geology, vol. 177, pp. 25-31, 2014.

[29] G. Walton, D. Labrie, and L. R. Alejano, "On the residual strength of rocks and rockmasses," Rock Mechanics and Rock Engineering, vol. 52, 2019.

[30] M. He, Z. Zhang, J. Zhu, N. Li, G. Li, and Y. Chen, "Correlation between the rockburst proneness and friction characteristics of rock materials and a new method for rockburst proneness prediction: field demonstration," Journal of Petroleum Science and Engineering, vol. 205, Article ID 108997, 2021.

[31] E. Detournay and P. Defourny, "A phenomenological model for the drilling action of drag bits," International Journal of Rock Mechanics and Mining Sciences \& Geomechanics Abstracts, vol. 29, no. 1, pp. 13-23, 1992.

[32] J. Kerisel, "Cours de mécanique des sols," Ecole National Des Ponts Et Chaussées, (in French), Paris, 1975.

[33] L. Gerbaud, S. Menand, and H. Sellami, "PDC bits: all comes from the cutter rock interaction," in Proceedings of the IADC/ SPE drilling conference. Society of Petroleum Engineers, No. SPE-98988-MS, Miami, FL, USA, 2006.

[34] E. Hoek, Practical Rock Engineering, Canada, North Vancouver, B.C, 2007.

[35] J. Arzúa and L. R. Alejano, "Dilation in granite during servo-controlled triaxial strength tests," International Journal of Rock Mechanics and Mining Sciences, vol. 61, no. 1, pp. 43-56, 2013.

[36] T. M. Warren, "Penetration rate performance of roller cone bits," SPE Drilling Engineering, vol. 2, no. 01, pp. 9-18, 1987.

[37] J. Arzúa, L. R. Alejano, and G. Walton, "Strength and dilation of jointed granite specimens in servo- controlled triaxial tests," International Journal of Rock Mechanics and Mining Sciences, vol. 69, pp. 93-104, 2014.

[38] G. Walton, "Scale effects observed in compression testing of Stanstead granite including post-peak strength and dilatancy," Geotechnical \& Geological Engineering, vol. 36, pp. 1091-1111, 2017.

[39] T. N. Gowd and F. Rummel, "Effect of confining pressure on the fracture behaviour of a porous rock," International Journal of Rock Mechanics and Mining Sciences \& Geomechanics Abstracts, vol. 17, no. 4, pp. 225-229, 1980.

[40] G. Walton, A. Hedayat, E. Kim, and D. Labrie, "Post-yield strength and dilatancy evolution across the brittle-ductile transition in Indiana limestone," Rock Mechanics and Rock Engineering, vol. 50, no. 7, pp. 1691-1710, 2017.

[41] S.-Q. Yang, H.-W. Jing, and S.-Y. Wang, "Experimental investigation on the strength, deformability, failure behavior and acoustic emission locations of red sandstone under triaxial compression," Rock Mechanics and Rock Engineering, vol. 45, no. 4, pp. 583-606, 2012.
[42] H. Masoumi, "Investigation into the Mechanical Behaviour of Intact Rock at Different Sizes," Ph.D. Thesis, University of New South Wales, Sydney, Australia, 2013.

[43] G. Walton, J. Arzúa, L. R. Alejano, and M. S. Diederichs, “A laboratory-testing-based study on the strength, deformability, and dilatancy of carbonate rocks at low confinement," Rock Mechanics and Rock Engineering, vol. 48, no. 3, pp. 941-958, 2015.

[44] R. Kumar, K. G. Sharma, and A. Varadarajan, "Post-peak response of some metamorphic rocks of India under high confining pressures," International Journal of Rock Mechanics and Mining Sciences, vol. 47, no. 8, pp. 1357-1362, 2010.

[45] R. J. Cuss, E. H. Rutter, and R. F. Holloway, "The application of critical state soil mechanics to the mechanical behaviour of porous sandstones," International Journal of Rock Mechanics and Mining Sciences, vol. 40, no. 6, pp. 847-862, 2003.

[46] M. Yumlu and M. U. Ozbay, "A study of the behaviour of brittle rocks under plane strain and triaxial loading conditions," International Journal of Rock Mechanics and Mining Sciences \& Geomechanics Abstracts, vol. 32, no. 7, pp. 725-733, 1995.

[47] F. Q. Gao and H. P. Kang, "Effects of pre-existing discontinuities on the residual strength of rock mass - insight from a discrete element method simulation," Journal of Structural Geology, vol. 85, pp. 40-50, 2016.

[48] S. Q. Yang, Y. Z. Jiang, W. Y. Xu, and X. Q. Chen, "Experimental investigation on strength and failure behavior of precracked marble under conventional triaxial compression," International Journal of Solids and Structures, vol. 45, no. 17, pp. 4796-4819, 2008. 